\title{
INTERAÇÃO HUMANO-MÁQUINA NO SISTEMA PRODUTIVO DA INDÚSTRIA 4.0 VISANDO AUMENTAR A PRODUTIVIDADE E REDUZIR LESÕES POR ESFORÇOS REPETITIVOS.
}

\author{
J. L. S. Moura ${ }^{1}$; ; R. A. Moura ${ }^{2}$ \\ 1 Universidade de Taubaté - UNITAU \\ Rua Daniel Danelli, s/n, Vila Nossa Senhora das Graças, Taubaté/SP, \\ CEP.: 12060-440, Brasil. (12) 3633-2165 \\ 2 Faculdade de Tecnologia de São José dos Campos - Professor Jessen Vidal \\ Av. Cesare Mansueto Giulio Lattes, 1350 - Eugênio de Melo, São José dos Campos/SP, \\ CEP: 12247-014, Brasil. Telefone: (12) 3905-2423 \\ *jon_losamo@hotmail.com
}

\begin{abstract}
RESUMO: Com o advento da indústria 4.0 ou era da digitalização e customização, surge uma forte tendência para se reduzir o tempo de desenvolvimento de novos produtos e prover aos humanos, um ambiente mais saudável de trabalho. Nesse viés, o uso de robôs colaborativos ou cobots, interagem diretamente com humanos, principalmente nos aspectos ergonômicos, pois as atividades repetitivas e monótonas são executadas pelos cobots, que por sua vez, são assistidos por computadores e dispositivos inteligentes, permitindo assim, que humanos e máquinas trabalhem colaborativamente. Este artigo de revisão, objetiva rever a adequação dos níveis de automação e a interação entre humanos e máquinas. $\mathrm{O}$ método contou com uma vasta revisão bibliográfica das publicações em revistas científicas nas últimas décadas. Os resultados demonstram ganhos expressivos no processo de montagem e conclui, que há ganhos ergonômicos e de produtividade na relação humanos e máquinas.
\end{abstract}

PALAVRAS-CHAVE: Interface humano-máquina; Produtividade; Cobots.

HUMAN-MACHINE INTERACTION AT THE INDUSTRY 4.0 ENVIRONMENT, AIMING TO INCREASE PRODUCTIVITY AND REDUCE INJURY CAUSED BY REPETITIVE EFFORTS.

ABSTRACT: With the advent of industry 4.0 or the era of digitization and customization, there is a strong tendency to reduce development time for new products and provide a healthier working environment for humans. In this bias, the use of collaborative robots or cobots interact directly with humans, especially in ergonomic aspects, because repetitive and monotonous activities are performed by cobots, which are assisted by computers and intelligent devices, thus allowing humans and machines work collaboratively. This review article aims to review the adequacy of automation levels and the interaction between humans and machines. The method has had a vast literature review of publications in scientific journals in recent decades. The results demonstrate significant gains in the assembly process and concludes that there are ergonomic and productivity gains in the human and machine relationship.

KEYWORDS: Human-machine interface; Productivity; Cobots.

\section{INTRODUÇÃO}




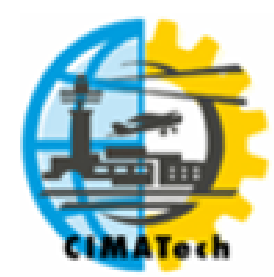

\section{ISSN $2447-5378$}

Dispositivos inteligentes são uma nova classe de híbridos que interagem direta e fisicamente com humanos e máquinas em espaços de trabalho únicos e compartilhados. Os robôs colaborativos ou simplesmente cobots, melhoram a segurança, a qualidade, a produtividade e a ergonomia, pela automatização e usos cobots nas atividades repetitivas e monótonas e assim poupando a fadiga humana (DEETER et al., 1997).

Interações humanos-máquinas em montagens com iteração direta, cooperação ou colaboração entre operadores e cobots em um único espaço de trabalho, é visto como uma das inovações e quebra de paradigma com alto potencial de automação em países cujos, altos salários, podem ser mitigados com a inclusão de máquinas nos processos produtivos. Assim os sistemas de montagem manuais podem ser sistematicamente combinados com cobots leves e sensíveis para atenderem demandas voláteis e sazonais do mercado com a possibilidade de permutarem ainda a sequência das atividades e tarefas automatizadas. $\mathrm{O}$ trabalho entre humano e robôs colaborativos representa uma nova tendência no campo industrial integrando o planejamento estratégico da indústria 4.0, e é reconhecida pelo acrônimo HRC cujo significado é humano e robô colaborativo (ZIPTER, 2014).

Os movimentos e movimentações dos robôs colaborativos são monitorados usando sensores avançados para não pôr em risco ou perigo o ser humano. Tal tecnologia, tem alto grau de confiabilidade e está disponível para o uso na produção, pois as aplicações, testes e validações passam por ensaios no mundo virtual e depois físico (WEISTOFFER, et al., 2014).

De uma forma geral os robôs colaborativos ou cobots, têm seu espaço ao substituir trabalhadores em tarefas perigosas e não ergonômicas, como por exemplo, manipulação de cargas pesadas e perigosas que são desconfortáveis e de alto risco para o trabalhador. Os cobots também podem ser instalados nas operações monótonas que são desconfortavelmente repetitivas ou exigem alta precisão, pois, são como são máquinas, têm mais resistência, agilidade e precisão, que permite completar suas tarefas mais rapidamente e com qualidade. Contudo, os cobots ainda não são capazes de pensar e só executam comandos após aprendizagem dos movimentos e portanto, são limitados a cumprir o que está na sua programação (GILLESPIE, COLGATE e PESHKIN, 2001).

\section{REVISÃO BIBLIOGRÁFICA}

A revolução industrial 4.0, está influenciando mundialmente as fábricas de diversos ramos, atividades e segmentos, iniciando um processo somente de ida para automatização das atividades repetitivas e que são executadas por humanos, aliviando destes, as atividades com esforços físicos e os posicionando no monitoramento e solução de problemas inesperados para tomarem decisões quando requeridos. O potencial de integração da realidade física e virtual embora reconhecida, ainda não está totalmente implementada. Em relação a mão de obra humana, países de economias avançadas e emergentes estimam reduzir mais de 5 milhões de empregos humanos, como por exemplo, na Volkswagen Eslováquia, onde está sendo construída uma nova plataforma que reduzirá de 2.500 para 250 funcionários e adiantam que o ser humano, precisará desenvolver um novo perfil profissional e necessitará de habilidades e qualificações para desempenhar com sucesso suas atividades laborais em uma fábrica altamente inovadora e digitalizada, onde, empregados e robôs colaborativos executarão suas atividades lado a lado (BENEŠOVÁ e TUPA, 2017).

Robôs colaborativos além de serem chamados de cobots, podem também serem chamados de robôs cooperativos ou ainda assistentes robóticos. Embora haja diferentes formas de chamá-los, todos são destinados à cooperação com humanos em conformidade com norma internacional de segurança, pois o cobot são equipados e possuem tecnologia embarcada como câmeras, sonares e sensores de proximidade (ISO/TS, 2016). 


\section{ISSN $2447-5378$}

Cobots se diferem dos robôs industriais, pois são robôs especiais, com propriedades cinemáticas e eixos com graus de liberdade que se adequam ao espaço de trabalho e interação física entre o cobot e o ser humano, pois, realizam movimentos precisos e suaves, sem machucar ou ferir o ser humano. Esta interface homem e máquina (IHM) pode também incorporar dispositivos a prova de erros para melhorar os índices de qualidade e dar maior confiabilidade ao processo sem impactar no design do produto final. No entanto projetar um local de trabalho colaborativo para humano-máquina é uma tarefa desafiadora, cujo resultado requer o conhecimento detalhado das atividades por parte de quem planeja, monta e viabiliza a execução do projeto (GILLESPIE, COLGATE e PESHKIN, 2001).

Segundo Matthias (2014), os robôs colaborativos também diferem dos manipuladores por serem projetados para ter seis ou sete graus de liberdade ou eixos de movimento para melhor se adequarem ao membro superior do corpo humano que tem até trinta graus de liberdade e cujo o resultado é uma grande amplitude de movimentos. Contudo há barreiras entre as atividades realizadas por um humano e uma máquina, o relacionamento se completa quando os robôs interagem nas atividades mais cansativas e os humanos interagem tomando decisões assertivas em prol da produtividade e qualidade da organização. Na Figura 1 é demonstrada a evolução durante as revoluções tecnológicas que ocorreram na égide industrial.

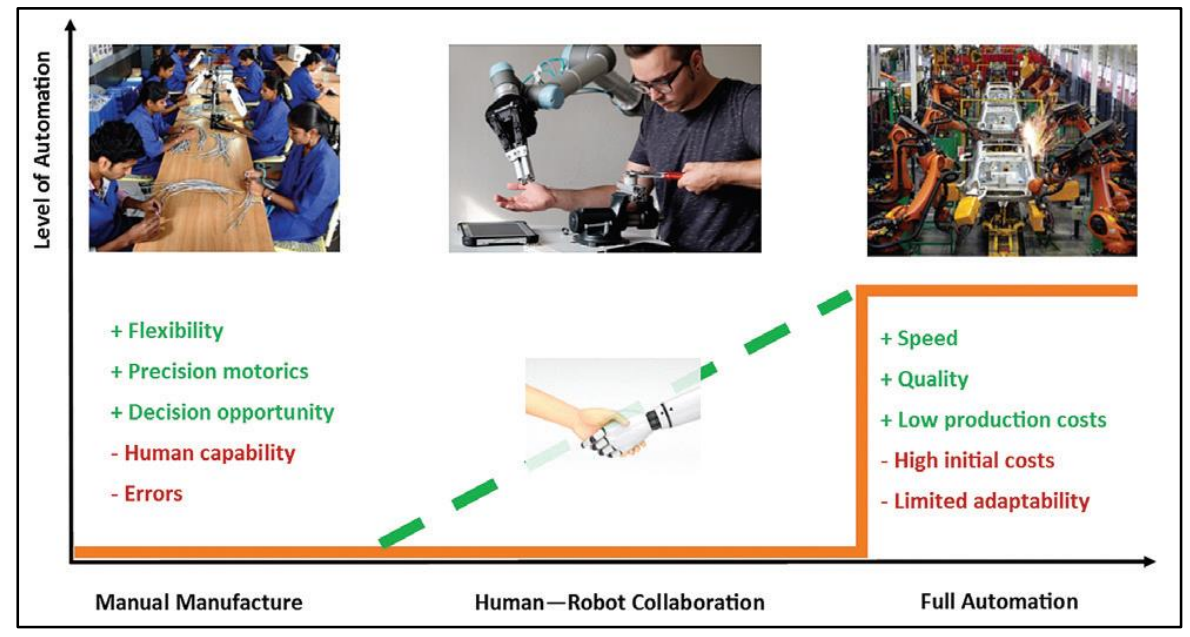

Figura 1. Nível de automação durante as revoluções industriais

Dispositivos periféricos melhoram a segurança entre humanos e máquinas nos locais de trabalho, ampliando o rol de atividades, complexidade e customização que são vistas como vantagens cruciais na perspectiva socioeconômica, ergonômica e para um ambiente de trabalho saudável. A implantação de robôs colaborativos na execução de atividades rotineiras e repetitivas reduz os custos operacionais e favorecem o uptime com menores níveis de paradas inesperadas por perda, erros e defeitos em comparação com países não automatizados, que ainda contam com mão de obra muito barata e, portanto o investimento em máquinas na produção não é vista como uma prioridade (BOLMSJÖ, DANIELSSON e SVENSSON, 2012).

A interação humano-máquina, permite que o trabalho seja padronizado e ininterrupto, movimentos precisos e automatização dos movimentos repetitivos e sequenciais que passam a ser executadas por um robô colaborativo, garantindo assim que a operação seja contínua e seu processo com uma melhor qualidade e menores ou nenhum índice de retrabalho pós-processamento no produto acabado (LACITY e WILLCOCKS, 2016; KOEPPE, 2014).

\subsection{Interação entre humano e máquina}




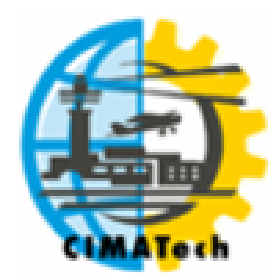

\section{ISSN $2447-5378$}

O robô colaborativo deve ser equipado com sensores ou radares que identifiquem a presença e parem ao reconhecer objetos ou humanos em sua trajetória, evitando assim avaria e colisão, pois o espaço de trabalho do cobot requer um alto nível de segurança. Desta forma, alertas ou alarmes sonoros, luminosos e paradas emergenciais a qualquer tempo e quando necessário, devem incorporar o projeto de um cobot (GLOCK, 2017; ISO/TS, 2016).

Uma célula colaborativa humano-máquina padrão possui uma barreira fixa e uma barreira virtual na forma de scanner ou cortina de luz para impedir que a máquina entre na área humano e que o humano se posicione na trajetória da máquina ou esteja muito próxima desta. Nesse sentido, a ideia de manter um espaço de trabalho com movimento exclusivo da máquina ou do humano, tem a tendência de mudar alocando humano e máquina na forma de cooperação compartilhada sob a condição de que o ser humano não seja colocando em posição de risco ou vulnerável no espaço de trabalho compartilhado (GLOCK, 2017).

A ISO/TS 15066 (2016) trata das normas de segurança para robôs e também dos dispositivos robóticos, compreendendo os tipos básicos da interação humanos e robôs colaborativos (HRC), onde os robôs colaborativos devem em projeto serem equipados com sensores, radares $\mathrm{e}$ dispositivos de paradas monitoradas com segurança para atender desde o tipo mais simples de colaboração até a mais complexa. Contudo, no espaço compartilhado há restrições e implicações onde a máquina e o humano ao executarem suas atividades ao mesmo tempo, devem atender as condições de iterações ou ciclos do processo para que a interação em um mesmo ambiente de trabalho atenda estritamente as especificações técnicas pré-determinadas e regulamentadas pelos órgãos competentes (MATTHIAS, 2014).

\subsection{Local de trabalho compartilhado}

O papel do ser humano na área onde cobot é uma tendência crescente, justifica-se pelos entraves corriqueiros e inerentes ao processo produtivo. Contudo requer que uma diretriz básica seja plenamente observada e atendida como quesito segurança, pois um robô em operação deve parar imediatamente, interrompendo sua atividade e trajetória quando houver risco de atingir um humano, ou seja, para evitar danos, colisão ou mesmo ferimentos fatais. No entanto, mesmo com tais limitações não é suficiente, pois, o robô colaborativo precisa ser atualizado e ter manutenção preventiva periódica e rotineira, com adoção de novos sensores e anteparos tecnológicos que detectem e evitem colisões. Como máquinas que são, os cobots, precisam receber os inputs de execução e devem ser configurados corretamente. No caso de uma configuração errada ou equivocada, os robôs colaborativos perdem as diretrizes de segurança e nesse ponto particular quem faz a programação e a aplica nas máquinas é responsável por uma parte significativa da segurança da interação humano-máquina (MATTHIAS, 2014).

Os robôs usados como assistentes melhoram a qualidade do trabalho por atingirem uma precisão de movimentos de montagem e pouparem o trabalhador humano nos vários campos de produção. É uma tarefa difícil para o ser humano seguir procedimentos e protocolos, mas não para os robôs colaborativos. A automação da atividade e a flexibilidade de movimentos que os graus de liberdade dos cobots permitem, facilita a detecção de detalhes e monitoramento de toda cadeia no sistema produtivo (ROBOTIQ, 2016).

Os países europeus através das iniciativas do programa horizonte 2020, buscam aumentar a competitividade industrial europeia com investimentos direcionados para a realização de fábricas inteligentes e autônomas, implementado processos inovadores e complexos, como a tecnologia do mundo virtual, catalisados pela internet das coisas (IoT) que possibilita integrar um sistema de dispositivos interconectados e inteligentes em tempo real para identificar e resolver problemas durante o processo interativo humano-máquina, leiautes e até em produtos antes de produzi-los fisicamente (MAGONE e MAZALI, 2016). 


\section{ISSN $2447-5378$}

A partir da fusão do mundo virtual e real, nasce um sistema chamado ciber-físico ou sistema cibernético-físico, composto de uma complexa rede de máquinas, produtos físicos, itens virtuais, facilidades de computação, armazenamento e dispositivos de comunicação que interagem entre si e exploram os enormes potenciais das novas tecnologias muitas das quais ainda inexploradas (BOLMSJÖ, DANIELSSON e SVENSSON, 2012).

Num contexto em que os paradigmas de mercado mudam radicalmente em pouco tempo, os esforços das empresas privadas e públicas devem estabelecer cadeias digitais de valor, como um elemento estratégico de recuperação, crescimento e aceleração. A transformação digital não pode representar apenas uma opção ou canal acessório, mas um elemento central para se concentrar, através da disseminação de habilidades, investimentos em pesquisa e medidas relativas à infraestrutura de conectividade, centro de dados e acesso à internet, evolução dos modelos operacionais, gestões coerentes com a cultura de empreendedorismo em empresas e organizações como startups (BOLMSJÖ, DANIELSSON e SVENSSON, 2012).

Uma inovação tecnológica ou organizacional não pode ser simplesmente uma ideia, um projeto, protótipo ou mesmo um novo produto, novo processo ou uma nova prática organizacional, mas deve ser traduzido na prática cotidiana, em procedimentos rotineiros e padronizados que permitam a produção eficiente com repetibilidade e acuracidade. A implementação do novo processo de produção e o exercício diário da nova prática organizacional, resulta em aprendizagem acadêmica e organizacional, através da qual uma organização adquire e divulga seu novo conhecimento e novos métodos voltados para a inovação, tecnologia, novos mercados, novas formas de operação e inevitavelmente uma nova estrutura organizacional (VIALE, 2008).

\subsection{Pilares tecnológicos da indústria 4.0}

Segundo Lu (2017), a indústria 4.0 consiste em uma transformação da produção industrial impulsionada pelos avanços tecnológicos, digitalização e internet das coisas, podendo até o momento, ser governada e orientada por nove pilares que representam o avanço tecnológico atual desta quarta revolução industrial, denominada indústria 4.0, conforme demonstrado na Figura 2.

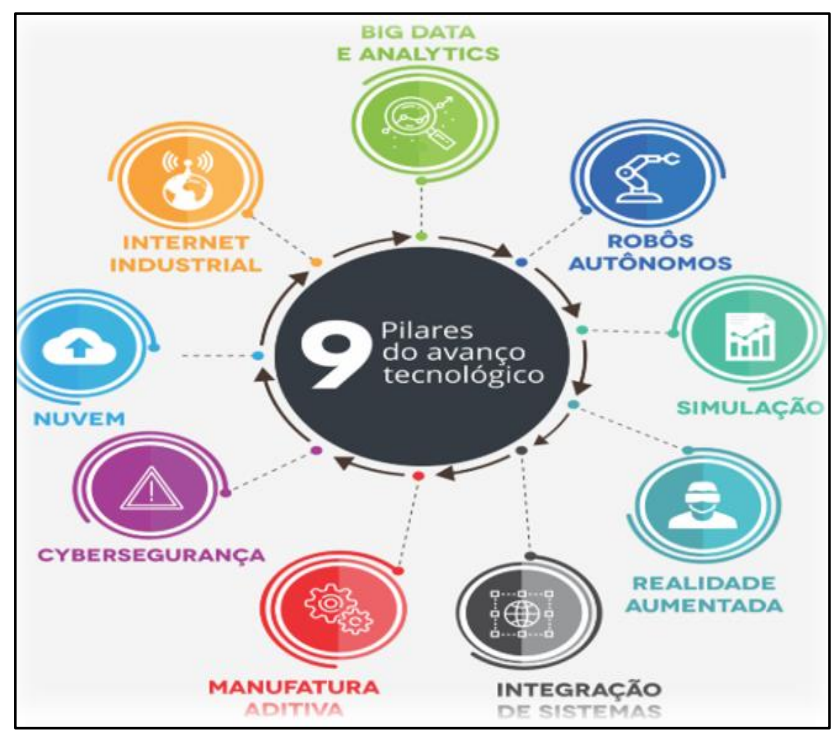

Figura 2. Pilares tecnológicos da $4^{\mathrm{a}}$ revolução industrial

As tecnologias digitais já permeiam fortemente o cotidiano de milhões de pessoas no mundo, desenvolvendo e oferecendo soluções técnicas e funcionais em um campo de negócios avançado e, em diferentes setores industriais como por exemplo a manufatura aditiva ou impressão 


\section{ISSN $2447-5378$}

3D que permite a concepção da produção e processos de forma integrada com as soluções tecnológicas disponíveis como a interação humano-máquina, esgotando o tema entre as disciplinas ergonomia e tecnologia da realidade aumentada que embora tratem de assuntos diversos, se completam, criando assim o conceito da ergonomia preventiva (MATTHIAS, 2014).

\subsection{Design ergonômico preventivo para a indústria 4.0}

A ergonomia e a antropometria por desconhecimento, não são utilizadas preventivamente contra doenças profissionais como a lesão por esforços repetitivos e o distúrbio osteomuscular relativo ao trabalho. Nesse sentido, quantificar e apresentar uma solução com base na biomecânica e na força dos músculos torna-se essencial, para preservação da saúde humana e o design do posto de trabalho precisa ser ergonômico na medida em que os conhecimentos científicos relativos ao homem são utilizados na concepção, com vistas a reduzir a fadiga física, facilitar a operação dos equipamentos e instrumentos, proporcionando segurança e conforto para os empregados com produtividade e mínimo absenteísmo (MOURA, et al., 2019).

A realidade aumentada e simulação virtual, contribuem para uma correta atividade ergonômica, baseando-se em uma abordagem multidisciplinar e enfatizando a interação entre diferentes habilidades e conhecimentos do mundo virtual. Por exemplo, um bom design ergonômico, deve integrar engenharia, tecnologia e medicina ocupacional, através de ferramentas avançadas por meio de atividades criativas, preventivas e inovadoras cujo objetivo é definir a qualidade, funcionalidade, durabilidade, visual, processos, serviços e seus sistemas ao longo de um ciclo de vida seguro e produtivo (WICKENS et al., 2012).

O design ou projeto é, portanto, o fator central do uso das tecnologias e fator crucial para o intercâmbio humano-máquina. Novas tecnologias transversais e difusas, representam um potencial inesgotável de inovação e solução de problemas relacionados à interação humano-máquina em trabalho compartilhados, complexos e que visam a eficiência, ergonomia e produtividade da transformação digital para o mundo real. Contudo, a ação de digitalizar suas operações e processos conceituais, tem sido um dos principais gargalos nas indústrias atualmente (ZHANG, 2005).

Nesse viés, as características cognitivas e psicológicas que afetam o conforto operacional e o leiaute virtual, do ponto de vista ergonômico cognitivo no design inicial, devem ser consideradas para se manter uma manufatura enxuta e isenta de desperdícios, com processos produtivos e operações menos onerosas e mais assertivas e principalmente alinhadas a interação homemmáquina (IHM). A troca e transmissão de informações entre humanos e máquinas no posto de trabalho colaborativo, é também um recurso necessário para o sucesso da interação e assim reforçar a importância de um leiaute industrial corretamente planejado (MAGONE e MAZALI, 2016).

Segundo Anderson (2012), a partir da perspectiva do conhecimento e seus aspectos cognitivos, os princípios de leiaute na integração humano-máquina podem ser presumidos como a colaboração, e as características cognitivas humanas quantificadas como limitações para a obtenção de respostas rápidas às questões inesperadas ao longo do processo. Assim, a nova interface humanomáquina deve reduzir a carga cognitiva das pessoas tanto quanto possível, tornando o produto fácil de aprender, fácil de usar e ser reproduzido e operacionalizado por máquinas com a mais alta eficiência produtiva (WICKENS et al., 2012).

Nesse sentido, reduzir a carga cognitiva para que um trabalhador possa aprender procedimentos de montagem dos produtos e controlar os sistemas diretamente no local, terão como objetivo facilitar o entendimento e a perspectiva de como os seres humanos deve integrar-se com objetos virtuais em um ambiente capaz de projetar um sistema que efetivamente e adequadamente aumente o desempenho humano através da detecção de necessidades cognitivas em vez das ações deliberadas em operações rotineiras e repetitivas e que passarão a serem executadas por máquinas colaborativas (BANGOR, KORTUM e MILLER, 2008). 


\section{ISSN $2447-5378$}

Robôs colaborativos estão sendo amplamente utilizados em campos industriais e em processos modernos. Com a chegada da era da digitalização, o desenvolvimento da indústria tem demandado por eficiência e precisão que os robôs colaborativos oferecem. Porém, é necessário um detalhado planejamento da trajetória como uma das maneiras mais importantes de se melhorar o desempenho dos movimentos dos robôs e salvaguardar de lesões e acidentes os humanos (HASHEMIANA, HOSSEINIB e NABAVIB 2017).

A cooperação humano-máquina nos processos de montagem no decorrer da quarta revolução industrial, facilitará a digitalização, implicando em melhorias não apenas na perspectiva das máquinas onde há um maior desenvolvimento, mas também nos dispositivos de realidade aumentada como objeto de simulação, treinamento e aprendizado, no intuito de preparar e capacitar os trabalhadores (LU, 2017; PAELKE, 2014).

\section{MATERIAIS E MÉTODOS}

Este artigo foi embasado em uma revisão bibliográfica no campo da gestão do conhecimento e pesquisadas científicas. Uma breve introdução do estudo empírico permitiu um relato detalhado da literatura, fornecendo apoio importante e revisões literárias com análise das três ultimas revoluções industriais para entender e se preparar para a quarta revolução industrial. Assim, as revisões são replicáveis e transparentes, pois se extrai informações gerais, como título, autor, detalhes da publicação e como as pesquisas específicas e cientificas tratam a informação, o método e suas notas sobre temas emergentes e correlacionados com a interação humano-máquina.

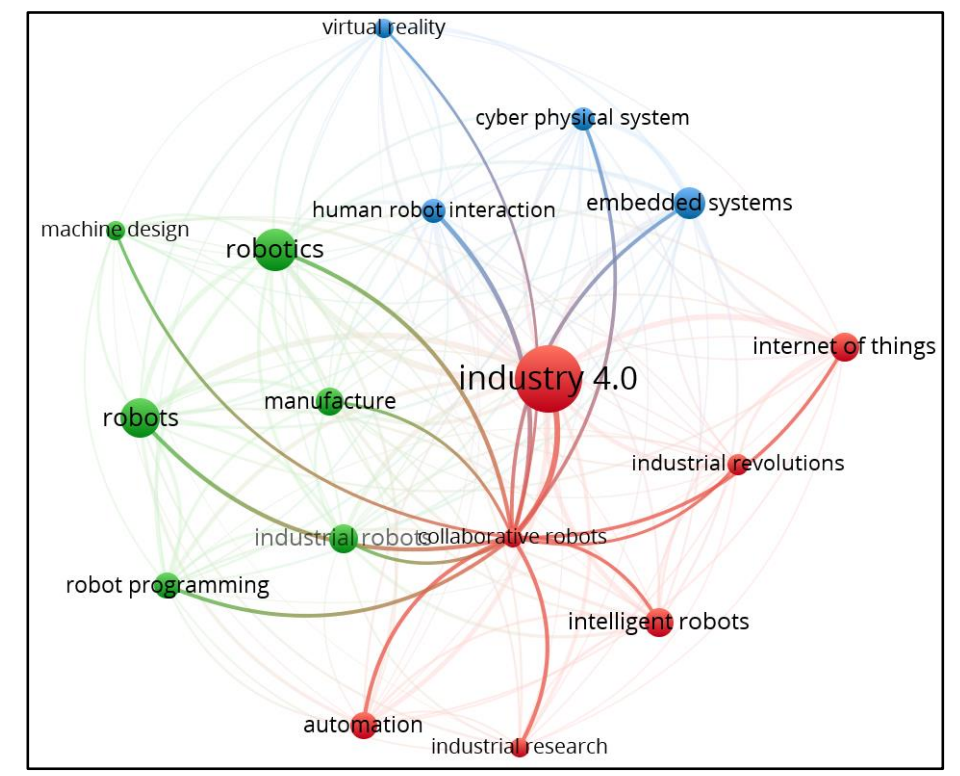

Figura 3. Software Vosviewer na consideração da interação humano-máquina

Usando a web em sua base de dados Scopus, foi possível visualizar uma pesquisa entre a integração humanos e robôs na indústria 4.0. As palavras-chave, indústria 4.0, robôs colaborativos, automação, integração humano-máquina foram identificadas em 146 artigos de revisão alusivos ao tema. Tais artigos divulgam e sugerem contribuições e atenuações dos princípios segurança, ergonomia, produtividade e qualidade além de observarem os riscos das profissões em relação as formas colaborativas e execução das atividades em parceria com robôs em uma mesma célula produtiva, provocando assim mudanças no perfil profissional e competências da força de trabalho. 


\section{RESULTADOS E DISCUSSÕES}

O desenvolvimento e implementação de sistemas robóticos que operam em módulo de colaboração entre humano e cobot enfatiza muitas questões que precisam ser abordadas de maneira apropriadas. Durante as revisões literárias verificou-se que na contextualização da quarta revolução industrial, uma nova configuração e papel do ser humano entra em cena para um relacionamento humano-máquina com a máxima interação como por exemplo, novas habilidades e competências, tecnologias digitais, segurança, proteção de dados, flexibilidade, interdisciplinaridade, tomadas de decisões, responsabilidade, conhecimento e comunicação em outros idiomas como inglês, mandarim e alemão, com pessoas trabalhando em equipe.

Especificamente, verifica-se que certas partes relacionadas as metodologias de trabalho consideram questões levantadas e análise dos riscos, bem como das rotinas para colaboração relevante durante a implementação e execução das tarefas.

$\mathrm{Na}$ Figura 4, é demonstrada a tendência do que é esperado do ser humano como um novo perfil para uma perfeita e completa relação humana-máquina com o advento da quarta revolução industrial, a chamada indústria 4.0.

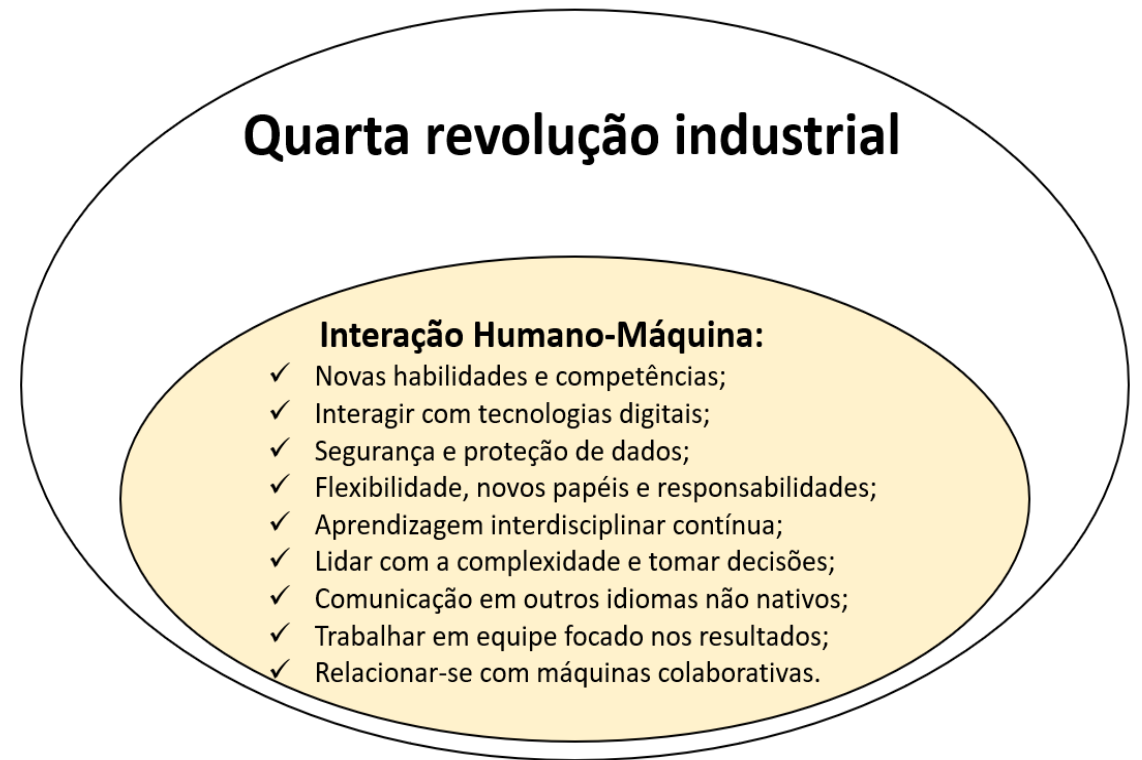

Figura 4. Interação humano-máquina no contexto da quarta revolução industrial

Como resultado deste artigo de revisão apresenta-se a possibilidade dos sistemas de produção serem interagidos por humanos e máquinas trabalhando lado a lado em colaboração plena motivada pela alta complexidade, aspectos ergonômicos e pelo fato de que os robôs colaborativos executam as atividades que mais requerem esforços e assim, operadores assumem a responsabilidade de monitorar e tomar decisões assertivas para situações inesperadas mas, que são inerentes ao processo produtivo.

\section{CONCLUSÕES}

Este trabalho abordou o uso de robôs colaborativos na indústria em operações repetitivas e determinísticas do ponto de vista de controle dentro de linhas de produção, separando os operadores e máquinas e ao mesmo forçando um trabalho em parceria, pois estarão lado a lado na mesma célula de trabalho. Embora os robôs colaborativos ou cobots sejam caracterizados por sua flexibilidade, os 


\section{ISSN $2447-5378$}

sistemas automatizados de produção geralmente não são tão flexíveis quanto esperados, pois para serem automatizados, os processos de trabalho devem ser razoáveis, simples e consistentes, e o volume de produção e tamanho de lote deve compensar o alto investimento inicial.

Os processos devem ser similares, assim como os produtos para tornar eficiente no uso do mesmo sistema relacionado aos hardwares e softwares, para que programas e algoritmos de controle possam ser adaptados, se necessário, para trabalhar com diferentes variantes em uma mesma célula produtiva em diferentes produtos, ou seja, atender plenamente a redefinição de mercado que customiza os produtos, com um mercado orientado para o consumidor, produtos personalizados e ciclos de vida mais curtos que tornam a interação humano-máquina mais desafiadora, exigindo máquinas autônomas e um novo perfil de trabalho para o ser humano.

Conclui-se que o sistema de produção na quarta revolução industrial será caracterizado pela necessidade de produzir produtos personalizados sob encomenda, ciclos de vida menores, que resultam em trocas frequentes entre produtos, obtidos pela interação humano e robôs colaborativos alinhados com os padrões de segurança e produtividade internacional.

\section{REFERÊNCIAS}

ANDERSON, J. R. Cognitive Psychology and It's Implications, edited by Y. L. Qin, Posts \& Telecom Press, 2012.

BANGOR, A.; KORTUM, P.T.; MILLER, J. T.; (2008) An empirical evaluation of the system usability scale. Int J Human-Comput Interact 24(6):574-594

BENEŠOVÁ, A., TUPA, J. Requirements for Education and Qualification of People in Industry 4.0. (2017) Procedia Manufacturing, 11, pp. 2195-2202. DOI: 10.1016/j.promfg.2017.07.366.

BOLMSJÖ, G.; DANIELSSON, F.; SVENSSON, B. Collaborative robots to support flexible operation in a manufacturing system, in: Proceedings of the Flexible Automation and Intelligent Manufacuturing Conference (FAIM2012), June 10-13 2012, Helsinki, Finland.

DEETER, T. E., G. J. KOURY, K. M. RABIDEAU, M. B. LEAHY, JR. AND T. P. TURNER. The next generation mutions handler advanced technology demonstrator program. IEEE ICRA, 1997.

GILLESPIE, R. B.; COLGATE, J. E.; PESHKIN, M. A. A general framework for cobot control. IEEE Trans. Robot. Automat., vol. 17, pp. 391-401, August, 2001.

GLOCK, C.H.; GROSSE, E. H.; NEUMANN, W. P.; SGARBOSSA, F. (2017) Editorial: human factors in industrial and logistic system design. Comput Indus Eng 111:463-466.

HASHEMIANA, A.; HOSSEINIB, S. F.; NABAVIB, S. N. (2017): Kinematically smoothing trajectories by NURBS reparameterization an innovative approach. Advanced Robotics, vol. 31, no. 23-24, pp. 1296-1312.

ISO/TS 15066. 2016. Robots and Robotic Devices - Industrial Safety Requirements Collaboration Industrial Robots. Disponível em: https://www.iso.org/standard/62996.html. Acesso em 10jun.2019. 


\section{ISSN $2447-5378$}

KOEPPE, R. K. New Industrial Robotics: Human and Robot collaboration for the factory. LETS 2014, Leading Enabling Technologies for Societal Challenges [online] Available from http://www.lets2014.eu/fileadmin/content/presentations/LETS_Koeppe_Final.pdf

LACITY, M. C., and WILlCOCKS, L. P. A New Approach to Automating Services. MIT Sloan Management Review, 58(1), 40-49. (2016a).

LU, Y. Industry 4.0: a survey on technologies, applications and open research issues. J. Ind. Inf. Integr. 2017; 6:1-10.

MAGONE, A.; MAZALI, T., (2016). Indústria 4.0 - Homens e máquinas na fábrica digital, Guerini e Associati. Escritório Europeu VDMA, (2016). Industrie 4.0: Dominando a Transição, 10 Principais Recomendações para um marco europeu para transição digital bem-sucedida na indústria.

MATTHIAS, B. Industrial Safety Requirements for Collaborative Robots and Applications. ERF 2014 - Workshop: Workspace Safety in Industrial Robotics: trends, integration and standards [online] Available from https://eurobotics.net/cms/upload/euRobotics_Forum/ERF2014_presentations/day_2/Industrial_HRC_-

ERF2014.pdf

MOURA, R. A.; JESUS, N. M. R.; SOUZA, R. S. Antropometria e ergonomia como ferramentas de vanguarda produtivas nas indústrias do futuro. Revista Sodebrás. Volume $\mathrm{n}^{\circ}$ 14. Edição $\mathrm{n}^{\circ} \quad 157 . \quad$ Janeiro/2019, p.109-112. $\quad$ ISSN. 1809-3957. DOI: https://doi.org/10.29367/issn.1809-3957.2019.157

PAELKE, V. Augmented reality in the smart factory: supporting workers in an industry 4.0 environment. IEEE 19th Conference on Emerging Technology and Factory Automation (ETFA). 2014. p. 1-4.

ROBOTIQ. Collaborative robots e-book [online] Available from http://robotiq.com/resourcecenter/ebooks/2016.

VIALE, R., (2008). A cultura da inovação, comportamentos inovadores e ambientes, Il Sole, Vol. 24.

WEISTOFFER, V., PALJIC, A., FUCHS, P. et al. Assessing the acceptability of human-robot copresence on assembly lines: A Comparison between actual situations and their virtual reality counterparts, Edinburgh: Robot and Human Interactive Communication, 2014 RO-MAN: The 23rd. IEEE International Symposium, ISBN 978-1-4799-6763-6.

WICKENS, C.; HOLLANDS, J. G.; BANBURY, S. AND PARASURAMAN, R. Engineering Psychology \& Human Performance, Pearson, London, UK, 4th edition, 2012.

ZHANG, Y. P. Human-computer interface design based on knowledge of cognitive psychology," Computer Engineering and Applications, vol. 30, pp. 105-107, 2005. 


\section{ISSN $2447-5378$}

ZIPTER, V. Entwicklung eines Planungs- und Optimierungssystems f ur den Einsatz sensitiver Roboter in der flexiblen Montage: Robot Farming. Techn. Univ., Diss.-Cottbus-Senftenberg, 2013, Shaker, Aachen, 2014. 